\title{
THE INFLUENCE OF CAPITAL STRUCTURE ON EARNING PER SHARE (EPS)
}

\author{
Eristy Minda Utami \\ Faculty of Business and Management, Widyatama University, Indonesia \\ Email: eristy.minda@widyatama.ac.id \\ Riski Taufik Hidayah \\ Faculty of Business and Management, Widyatama University, Indonesia \\ Email: riski.taufik@widyatama.ac.id
}

\begin{abstract}
The purposes of this research are finding the influence of Capital Structure on Earning Per Share partially and simultaneously. The research method used is descriptive analysis verificative using secondary data. Statistic method is using multiple correlation regression statistic method to test the effect of indenpendent variables (capital structure) on the dependent variable (Earning Per Share) on Jakarta Islamic Index (JII) 2011 - 2016. Results of research using a significance level of 0.95 and 0.05 error rate indicates that the capital structure represented by the ratio of DAR has no effect on Earning Per Share (EPS), DER also has no effect on Earning Per Share (EPS), LDAR has a negative effect on EPS. The effect of capital structure on an EPS of $32.0 \%$ and the remaining $68.0 \%$ influenced by other factors not examined in this study.
\end{abstract}

Keywords: Debt to Asset Ratio (DAR), Debt to Equity Ratio(DER), Long-term Debt to Asset Ratio(LDAR), Capital Structure, Earning Per Share (EPS) 


\section{PENDAHULUAN}

Persaingan bisnis yang semakin ketat menuntut semua perusahaan dapat bertahan dalam kondisi tersebut. Persaingan ini juga berdampak pada berbagai indeks yang berisi saham pilihan. Indeks yang berisi saham-saham blue chips tidak menjamin bahwa kinerjanya akan selalu cemerlang. Dampak dari persaingan tersebut juga dirasakan oleh berbagai indeks seperti LQ 45 dan JII.

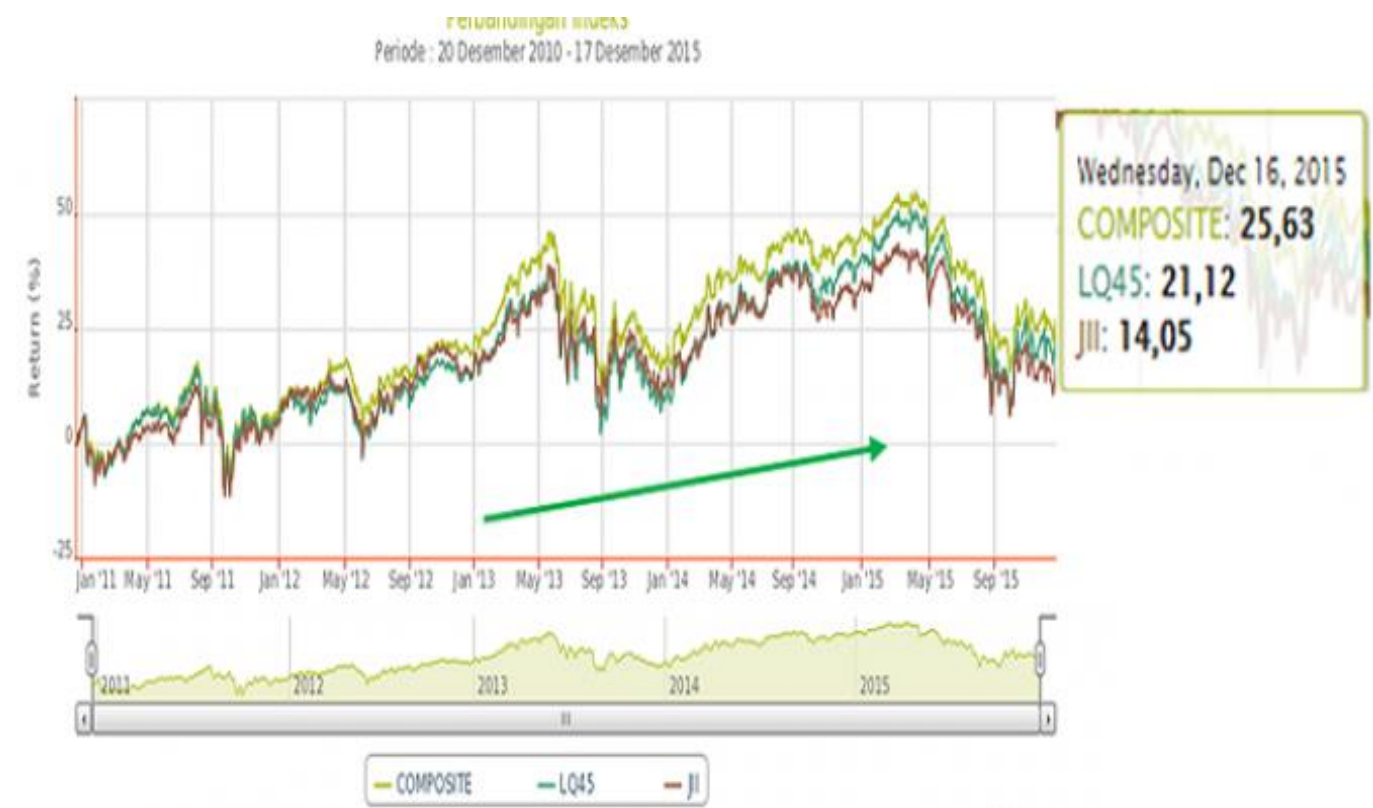

Gambar 1: Perkembangan Indeks

Sumber: Diolah Bareksa, (2017)

Pada tahun 2011-2015 perkembangan return saham Jakarta Islamic Index (JII) secara rata-rata masih lebih kecil dari kumpulan saham secara keseluruhan. Indeks saham syariah yang diwakili JII hanya mencatatkan imbal hasil (return) 14,05 persen, jauh di bawah IHSG yang memberikan return 25,63 persen. (http://www.bareksa.com)

Perusahaan yang termasuk dalam JII ini juga harus tetap bekerja keras mengelola aktivitasnya untuk mampu bersaing demi meraih tujuannya. Setiap perusahaan pada umumnya mempunyai tujuan yang sama yaitu memaksimalkan kemakmuran para pemegang sahamnya yang dapat diukur dari Earning Per Share (EPS). Earning Per Share atau laba per lembar saham merupakan ukuran 
kemampuan perusahaan untuk menghasilkan keuntungan per lembar saham pemilik. Tujuan tersebut semestinya menjadi dasar dalam melakukan analisis dan tindakan rasional dalam proses pengambilan keputusan yang akan dibuat oleh manajemen perusahaan.

Salah satu keputusan yang harus dibuat oleh perusahaan adalah keputusan pendanaan. Agar perusahaan dapat bertahan hidup dan berkembang, maka pihak manajemen perusahaan berusaha mendapatkan dana yang dibutuhkan. Pada dasarnya, setiap perusahaan pasti membutuhkan dana untuk menjalankan kegiatan operasinya. Dana tersebut bisa didapat dari internal perusahaan dan dari eksternal perusahaan seperti pinjaman. Keputusan pendanaan tersebut tentunya akan mempengaruhi keadaan struktur modal perusahaan. Struktur modal merupakan proporsi antara modal sendiri dan pinjaman. Kesalahan struktur modal akan berdampak luas terutama apabila perusahaan terlalu besar dalam menggunakan hutang, sehingga beban tetap yang harus ditanggung perusahaan semakin besar pula. Hal ini juga berarti akan meningkatkan risiko finansial, yaitu risiko saat perusahaan tidak membayar beban bunga atau angsuran hutang-hutangnya. Oleh karena itu, perusahaan membutuhkan struktur modal yang optimal baik itu dari modal sendiri maupun dari hutang agar menghasilkan struktur modal yang terbaik yang dapat meningkatkan kesejahteraan pemilik yang tercermin dalam nilai EPS.

Dalam menetapkan struktur modal sebaiknya juga diperhatikan beberapa variabel, yang dapat diukur oleh rasio struktur modal seperti Debt to Asset Ratio (DAR), Debt to Equity Ratio (DER), Long-term Debt to Asset Ratio (LDAR). Pengaruh dari variabel-variabel tersebut dapat menjelaskan sejauh mana struktur modal mempengaruhi nilai dan tujuan perusahaan untuk memakmurkan para investor.

\section{Rumusan Masalah}

1. Bagaimana pengaruh Debt to Asset Ratio terhadap Earning Per Share pada Jakarta Islamic Index (JII) periode 2011-2016?

2. Bagaimana pengaruh Debt to Equity Ratio terhadap Earning Per Share pada Jakarta Islamic Index (JII) periode 2011-2016? 
3. Bagaimana pengaruh Long-term Debt to Asset Ratio terhadap Earning Per Share pada Jakarta Islamic Index (JII) periode 2011-2016?

4. Bagaimana pengaruh Debt to Asset Ratio, Debt to Equity Ratio, dan Longterm Debt to Asset Ratio terhadap Earning Per Share pada Jakarta Islamic Index (JII) periode 2011-2016?

\section{Tujuan Penelitian}

1. Untuk mengetahui pengaruh Debt to Asset Ratio terhadap Earning Per Share pada Jakarta Islamic Index (JII) periode 2011-2016?

2. Untuk mengetahui pengaruh Debt to Equity Ratio terhadap Earning Per Share pada Jakarta Islamic Index (JII) periode 2011-2016

3. Untuk mengetahui pengaruh Long-term Debt to Asset Ratio terhadap Earning Per Share pada Jakarta Islamic Index (JII) periode 2011-2016?

4. Untuk mengetahui pengaruh Debt to Asset Ratio, Debt to Equity Ratio, dan Long-term Debt to Asset Ratio terhadap Earning Per Share pada Jakarta Islamic Index (JII) periode 2011-2016?

\section{KAJIAN PUSTAKA}

\section{Struktur Modal}

"Struktur modal merupakan perimbangan antara penggunaan modal pinjaman yang terdiri dari utang jangka pendek yang bersifat permanen, utang jangka panjang, dengan modal sendiri yang terdiri dari saham preferen dan saham biasa" (Sjahrial 2014: 250).

Hal ini sejalan dengan Gitman (2012;508) yang menyatakan "Capital structure id the mix of long-term debt and equity mantaines by the firm"

Menurut Sutrisno (2012:255) "struktur modal merupakan imbangan antara modal asing atau hutang dengan modal sendiri.

\section{Teori Struktur Modal}

Menurut Hanafi $(2014 ; 297)$ teori struktur modal terdapat 6 (enam) pendekatan, yaitu:

1. Pendekatan Tradisional

Pendekatan tradisional berpendapat akan adanya struktur modal yang optimal. Dengan kata lain struktur modal mempunyai pengaruh terhadap nilai perusahaan. 
Struktur modal bisa diubah-ubah agar bisa diperoleh nilai perusahaan yang optimal.

\section{Pendekatan Modigliani dan Miller (MM)}

Pada tahun 1950-an, dua orang ekonom menentang pandangan tradisional struktur modal. Mereka berpendapat bahwa struktur modal tidak mempengaruhi nilai perusahaan. Kemudian pada awal tahun 1960-an, kedua ekonom tersebut memasukkan faktor pajak ke dalam analisis mereka. Mereka berkesimpulan bahwa nilai perusahaan dengan utang lebih tinggi di bandingkan nilai perusahaan tanpa utang. Kenaikan nilai tersebut dikarenakan adanya penghematan pajak dari penggunaan utang.

\section{Teori Trade Off dalam Struktur Modal}

Ada hal-hal yang membuat perusahaan tidak bisa menggunakan utang sebanyakbanyaknya. Satu hal yang terpenting adalah dengan semakin tingginya utang, akan semakin tinggi kemungkinan kebangkrutan. Hal ini disebabkan semakin tinggi utang, semakin besar bunga yang harus dibayarkan.

\section{Model Miller dengan Pajak Perusahaan dan Personal}

Modigliani dan Miller mengembangkan model struktur modal tanpa pajak dan dengan pajak. Nilai perusahaan dengan pajak lebih tinggi dibandingkan dengan nilai perusahaan tanpa pajak. Selisih tersebut diperoleh melalui penghematan pajak karena bunga bisa dipakai untuk mengurangi pajak.

\section{Pecking Order Theory}

Seorang akademisi, Donald Donaldson (1961) melakukan pengamatan terhadap perilaku struktur modal di Amerika Serikat. Pengamatannya menunjukkan bahwa perusahaan yang mempunyai keuntungan yang tinggi ternyata cenderung menggunakan utang lebih rendah.

6. Teori asimetri Informasi dan Signaling

Konsep signaling dan asimetri informasi berkaitan erat. Teori asimetri mengatakan bahwa pihak-pihak yang berkaitan dengan perusahaan tidak mempunyai informasi yang sama mengenai prospek dan risiko perusahaan. Pihak tertentu mempunyai informasi yang lebih baik dibandingkan pihak lainnya. Manajer biasanya mempunyai informasi yang lebih baik dibandingkan dengan 
pihak luar (seperti investor). Investor, yang merasa mempunyai informasi yang lebih sedikit, akan berusaha menginterprestasikan perilaku manajer. Dengan kata lain, perilaku manajer, termasuk dalam hal menentukan struktur modal, bisa dianggap sebagai signal oleh pihak luar (investor).

\section{Rasio Struktur Modal}

Menurut Sjahrial dan Purba (2013: 37) rasio struktur modal terdiri dari:

1. Rasio Total Utang Terhadap Total Aktiva (Total Debt to Total Assets Ratio/DAR)

Rasio ini digunakan untuk mengukur seberapa besar jumlah aktiva perusahaan dibiayai dengan utang. Semakin tinggi rasio ini berarti semakin besar jumlah modal pinjaman yang digunakan untuk investasi pada aktiva guna menghasilkan keuntungan bagi perusahaan.

Van horn dan wachowicz (2012:176) menjelaskan semakin tinggi rasio utang terhadap total asset, semakin besar risiko keuangannya, semakin rendah rasio maka semakin rendah risikonya.

Menurut Kasmir (2014:156) apabila rasionya tinggi, artinya pendanaan dengan utang semakin banyak, maka semakin sulit bagi perusahaan untuk memperoleh tambahan pinjaman karena dikhawatirkan perusahaan tidak mampu menutupi utang-utangnya dengan aktiva yang dimilikinya.

Debt to Asset Ratio $=\frac{\text { Totaliebst }}{\text { TotalAeset }} \times 100 \%$

\section{Rasio Total Utang Terhadap Modal (Total Debt to Equity Ratio/DER)}

Rasio ini digunakan untuk mengukur perimbangan antara kewajiban yang dimiliki perusahaan dengan modal sendiri. Rasio ini juga dapat berarti sebagai kemampuan perusahaan dalam memenuhi kewajiban membayar utangnya dengan jaminan modal sendiri.

Sejalan dengan Harahap (2013:303) "Debt to Equity Ratio menggambarkan sampai sejauh mana modal pemilik dapat menutupi utang-utang kepada pihak luar"

Semakin tinggi DER menunjukkan semakin besar total hutang terhadap total ekuitas, juga akan menunjukkan semakin besar ketergantungan perusahaan terhadap pihak luar (kreditur) sehingga tingkat resiko perusahaan semakin besar. 
Debt to Equity Ratio $=\frac{\text { Totaldebt }}{\text { Totalequity }} \times 100 \%$

3.Rasio Total Utang Jangka Panjang Terhadap Aset (Long-term Debt to Asset Ratio/LDAR)

Tujuannya adalah untuk mengukur berapa bagian dari setiap rupiah asset yang dijadikan jaminan hutang jangka panjang dengan cara membandingkan antara hutang jangka panjang dengan total aset yang disediakan oleh perusahaan. (Kasmir, 2014)

Perusahaan perlu mewaspadai jumlah hutang jangka panjang yang kemungkinan bisa meningkat dari tahun ke tahun, besarnya rasio ini akan berpengaruh pada keputusan investor.

Semakin kecil akan semakin bagus nilainya untuk perusahaan, karena dinilai mampu mengatasi kesulitan keuangan dengan meminjam hutang jangka panjang tidak dalam jumlah besar. Rumus untuk mencari rasio ini adalah sebagai berikut :

Long-term Debt to Asset Ratio $=\frac{\text { Total Long-term Debt }}{\text { Total Asset }} \times 100 \%$

Earning Per Share

Menurut Gitman (2012:81) definisi dari Earning Per Share (EPS) ialah: “The firm's Earning Per Share (EPS) is generally of interest to present or perspective stockholders and management. As we note earning, EPS represent the number of dollars earned during the period on behalf og each outstanding share of common stock"

Definisi lain menurut Kasmir (2014) tentang Earning Per Share (EPS) adalah "EPS adalah rasio untuk mengukur keberhasilan manajemen dalam mencapai keuntungan bagi pemegang saham. Rasio yang rendah berarti manajemen belum berhasil untuk memuaskan pemegang saham, sebaliknya dengan rasio yang tinggi maka kesejahteraan pemegang saham meningkat"

\section{Hipotesis}

Berdasarkan penjelasan tersebut diatas, maka penulis mengambil beberapa hipotesis yang dijadikan acuan dalam pelaksanaan penelitian ini, yaitu sebagai berikut:

$\mathrm{H}_{1}$ : Debt to Asset Ratio mempunyai pengaruh terhadap EPS

$\mathrm{H}_{2}$ : Debt to Equity Ratio mempunyai pengaruh terhadap EPS 
$\mathrm{H}_{3}$ : Long-term debt to Asset Ratio mempunyai pengaruh terhadap EPS $\mathrm{H}_{4}$ : Debt to Asset Ratio, Debt to Equity Ratio dan Long-term debt to Asset Ratio mempunyai pengaruh terhadap EPS

\section{METODE PENELITIAN}

Metode penelitian yang akan digunakan pada penelitian kali ini yaitu metode deskriptif dan verifikatif. Dalam pelaksanaan analisis penulis memanfaatkan analisis regresi berganda. Teknik pengambilan sampel yang digunakan adalah puposive sampling yaitu memilih sampel berdasarkan kesesuaian karakteristik sampel dengan kriteria pemilihan tertentu.

Kriteria-kriteria pemilihan sampel yang digunakan pada penelitian ini antara lain:

1. Perusahaan yang tergabung kedalam Jakarta Islamic Index (JII) di Bursa Efek Indonesia tahun 2011-2016.

2. Perusahaan yang terus-menerus muncul dalam kelompok JII selama kurun waktu 12 periode 2011-2016.

3. Perusahaan yang memiliki data yang lengkap yang diperlukan dalam penelitian ini.

Berdasarkan kriteria tersebut di atas diperoleh sejumlah sampel yang memenuhi syarat yaitu sebanyak 10 perusahaan, diantaranya:

Tabel 1. Daftar Sampel Perusahaan JII 2011-2016

\begin{tabular}{clc}
\hline No & \multicolumn{1}{c}{ Emiten } & Kode Saham \\
\hline 1 & PT Astra Agro Lestari Tbk. & AALI \\
2 & PT Astra International Tbk. & ASII \\
3 & PT Alam Sutera Realty Tbk. & ASRI \\
4 & PT indocement Tunggal Perkasa Tbk. & INTP \\
5 & PT Kalbe Farma Tbk. & KLBF \\
6 & PT Lippo Karawaci Tbk. & LPKR \\
7 & PT London Sumatera Tbk. & LSIP \\
8 & PT Telekomunikasi Indonesia Tbk. & TLKM \\
9 & PT United Tractors Tbk. & UNTR \\
10 & PT Unilever Indonesia Tbk. & UNVR
\end{tabular}

Sumber : Data diolah peneliti, 2017 


\section{HASIL DAN PEMBAHASAN}

\section{Analisis Deskriptif}

Dalam penelitian ini terdapat 4 variabel, dimana Debt to Asset Ratio, Debt to Equity Ratio, dan Long-term Debt to Asset Ratio sebagai variable bebas atau independen dan Earning Per Share sebagai variable terikat atau dependen. Berikut ini disajikan data deskriptif keempat variabel tersebut yang meliputi nilai rata-rata, standar deviasi, serta nilai tertinggi dan terendah.

Tabel 2. Analisis Deskriptif Variabel Penelitian

\begin{tabular}{lrrrrr}
\hline \multicolumn{5}{c}{ Descriptive Statistics } \\
\hline & $\mathrm{N}$ & \multicolumn{1}{c}{ Minimum } & Maximum & \multicolumn{1}{c}{ Mean } & Std. Deviation \\
\hline DAR & 60 & 13,31 & 71,91 & 39,0583 & 18,16423 \\
DER & 60 & 15,35 & 255,97 & 82,9467 & 62,81792 \\
LTDR & 60 &, 40 & 47,38 & 14,9802 & 13,49371 \\
EPS & 60 & 23,51 & 1657,00 & 557,1060 & 543,12935 \\
Valid N (listwise) & 60 & & & &
\end{tabular}

Sumber : Data diolah peneliti, 2017

Pada tabel 2 dapat dilihat rata-rata Debt to Asset Ratio perusahaan yang tergabung kedalam Jakarta Islamic Index sebesar 39,06\% dengan kisaran nilai antara $13,31 \%$ hingga $71,91 \%$. Data ini menunjukkan secara rata-rata hutang perusahaan yang tergabung dalam Jakarta Islamic Index mencapai 39,06\% dari total asset perusahaan. Debt to Asset Ratio tertinggi dimiliki PT.Unilever Indonesia Tbk, sebaliknya Debt to Asset Ratio paling rendah dimiliki oleh PT Indocement Tunggal Perkasa Tbk.

Selanjutnya rata-rata dari Debt to Equity Ratio perusahaan yang tergabung dalam Jakarta Islamic Index sebesar 82,95\% dengan kisaran nilai antara 15,35\% hingga $255,97 \%$. Data ini menunjukkan bahwa secara rata-rata hutang perusahaan yang tergabung kedalam Jakarta Islamic Index mencapai 82,95\% dari jumlah modal yang dimiliki perusahaan. PT.Unilever Indonesia Tbk memiliki Debt to Equity Ratio tertinggi, sebaliknya Debt to Equity Ratio yang paling rendah dimiliki PT Indocement Tunggal Perkasa Tbk.

Rata-rata Long-term Debt to Asset Ratio perusahaan yang tergabung kedalam Jakarta Islamic Index sebesar $14,98 \%$ dengan kisaran nilai antara 0,4\% 
hingga 47,38\%. Long-term Debt to Asset Ratio tertinggi dimiliki PT Lippo Karawaci Tbk, sebaliknya Long-term debt to Asset Ratio terendah dimiliki PT Kalbe Farma Tbk. Data ini menggambarkan bahwa secara rata-rata hutang jangka panjang perusahaan yang tergabung dalam Jakarta Islamic Index mencapai $14,98 \%$ dari total asset perusahaan.

Laba perlembar saham yang tergabung dalam secara rata-rata sebesar Rp 557,11 dengan kisaran nilai antara Rp 23,5 hingga Rp 1657. Laba perlembar saham paling tinggi diraih PT United Tractors Tbk, sebaliknya laba perlembar saham terendah diraih PT Alam Sutera Realty Tbk.

\section{Hasil Uji Asumsi Klasik}

Tabel 3. One-Sample Kolmogornov-Smirnov Test

\begin{tabular}{llr}
\hline & & \multicolumn{2}{c}{$\begin{array}{c}\text { Unstandardized } \\
\text { Residual }\end{array}$} \\
\hline $\mathrm{N}$ & Mean & 60 \\
Normal Parameters & $0 \mathrm{E}-7$ \\
& Std. Deviation & 1,13191737 \\
Most Extreme Differences & Absolute &, 106 \\
& Positive &, 083 \\
Kolmogornov-Smirnov Z & Negative &,- 106 \\
Asymp. Sig (2-tailed) & &, 824 \\
a. Test distribution is Normal. &, 505 \\
b. Calculated from data. & & \\
\hline
\end{tabular}

Sumber : Data diolah peneliti, 2017

Pengujian asumsi klasik dilakukan terlebih dahulu dan kemudian dilanjutkan dengan pengujian hipotesis. Pengujian ini bertujuan untuk melakukan pengujian kesahihan dan keabsahan model regresi hasil estimasi. Beberapa asumsi klasik yang harus terpenuhi diantaranya adalah uji normalitas, uji multikolinieritas, uji heteroskedastisitas dan uji autokorelasi. Hasil uji normalitas dengan memakai uji Kolmogornov-Smirnov (KV) didapatkan nilai signifikansi sebesar 0,505. Nilai uji KV tersebut lebih besar dari tingkat kekeliruan sebesar 5\% $(0,05)$, maka dapat diambil sebuah kesimpulan bahwa model regresi berdistribusi normal. Kemudian hasil uji multikolinieritas mampu menunjukkan adanya korelasi yang kuat antara sesama variabel independen. Uji autokorelasi menggunakan nilai Durbin-Watson jatuh pada daerah tidak ada keputusan, namun dari hasil uji lanjutan menggunakan runs test dipastikan tidak terjadi autokorelasi. 
Terakhir hasil uji heteroskedastisitas menggunakan scattler plot menunjukkan tidak ada pola tertentu pada grafik plot antara nilai prediksi variabel terikat (ZPRED) dengan residual (SDRESID) sehingga bisa ditarik kesimpulan terjadi gejala heteroskedastisitas pada model regresi.

\section{Hasil Uji Hipotesis}

\section{Uji t}

Dalam pelaksanaan pengujian secara parsial akan diuji pengaruh setiap variabel independen terhadap variabel dependen. Statistik uji yang akan digunakan pada pengujian ini adalah uji t. Nilai tabel yang digunakan sebagai nilai kritis sebesar 2,00 yang didapatkan dari tabel t pada $\alpha=0,05$ dan derajat bebas 56 untuk pengujian dua arah. Nilai statistik uji yang tertera pada tabel 4 selanjutnya akan dibandingkan dengan nilai $t_{\text {tabel }}$ untuk menguji apakah variabel independen yang sedang diuji berpengaruh signifikan atau tidak.

Tabel 4. Coefficients ${ }^{\mathrm{a}}$

\begin{tabular}{|c|c|c|c|c|c|c|c|c|}
\hline \multirow{2}{*}{\multicolumn{2}{|c|}{ Model }} & \multicolumn{2}{|c|}{$\begin{array}{l}\text { Unstandardized } \\
\text { Coefficients }\end{array}$} & \multirow{2}{*}{$\begin{array}{c}\text { Standardized } \\
\text { Coefficients } \\
\text { Beta }\end{array}$} & \multirow[t]{2}{*}{$\mathrm{t}$} & \multirow[t]{2}{*}{ Sig. } & \multicolumn{2}{|c|}{ Collinearity Statistics } \\
\hline & & B & Std. Error & & & & Tolerance & VIF \\
\hline 1 & (Constant) & 5,424 &, 568 & & 9,545 & ,000 & & \\
\hline & DAR & ,060 & , 035 & ,780 & 1,728 & , 090 & 057 & 17,670 \\
\hline & DER &,- 012 & ,009 &,- 551 & $-1,334$ & 188 & ,068 & 14,768 \\
\hline & LTDR &,- 079 & ,015 &,- 756 & $-5,172$ &, 000 &, 540 & 1,852 \\
\hline
\end{tabular}

a.Dependent Variable: Ln_EPS

Sumber : Data diolah peneliti, 2017

Berdasarkan hasil pengolahan seperti yang terdapat pada table 4 diperoleh nilai thitung dari variable Debt to Asset Ratio sebesar 1,728 dengan nilai probability sebesar 0,090. Karena $t_{\text {hitung }}(1,728)$ lebih kecil dari $t_{\text {tabel }}(2,00)$, maka pada tingkat signifikansi 5\% diputuskan untuk menerima Ho yang berarti Ha ditolak. Dengan demikian dapat disimpulkan bahwa Debt to Asset Ratio (DAR) tidak memiliki pengaruh terhadap Earning Per Share pada perusahaan yang tergabung dalam Jakarta Islamic Index. Hal ini sejalan dengan hasil penelitian Kamila (2016). DAR merupakan sebuah rasio keuangan yang dapat digunakan untuk mengukur seberapa besar hutang membiayai aktiva perusahaan atau seberapa besar hutang perusahaan berpengaruh pada pengelolaan aktiva. DAR positif menunjukkan hubungan yang searah antara X1 dengan variable Y. Jika DAR naik, maka EPS 
akan naik, dan sebaliknya. Rasio yang tinggi tidak membuat perusahaan kesulitan dalam memperoleh penambahan pinjaman karena perusahaan dianggap mampu menutupi pinjaman-pinjamannya menggunakan aktiva yang dimilikinya. Hal ini tentunya akan menjadi pertimbangan yang positif bagi para investor di pasar modal.

Hasil yang terdapat pada tabel 4 juga menunjukkan nilai $t_{\text {hitung }}$ dari variabel Debt to Equity Ratio yaitu sebesar -1,334 dengan nilai probability sebesar 0,188. Karena nilai absolut $t_{\text {hitung }}(1,334)$ lebih kecil dari $t_{\text {tabel }}(2,00)$, maka pada tingkat signifikansi 0,05 diperoleh keputusan untuk menerima Ho yang berarti menolak Ha. Dengan demikian bisa ditarik kesimpulan Debt to Equity Ratio tidak berpengaruh terhadap Earning Per Share pada perusahaan yang tergabung kedalam Jakarta Islamic Index. Hal ini sejalan dengan hasil penelitian Mohamad et all (2015) dan Kamila (2016). DER yang negatif berarti adanya hubungan yang tidak searah antara X2 dan Y. Penggunaan ekuitas mempunyai dampak yang buruk terhadap kinerja perusahaan apabila perusahaan tidak memanfaatkan dana dengan baik. Semakin tinggi DER maka risiko perusahaan relatif lebih tinggi karena perusahaan memiliki beban hutang dan bunga yang tinggi dalam menjalankan kegiatan operasinya. Risiko yang tinggi akan membuat investor menginginkan return yang tinggi pula. Rasio yang tinggi juga cenderung akan membuat perusahaan kesulitan dalam mendapatkan penambahan pinjaman karena adanya kecenderungan perusahaan tidak sanggup menutupi hutang-hutangnya. Hal ini memungkinkan terjadinya penurunan kinerja perusahaan dikarenakan perusahaan memiliki tingkat ketergantungan yang semakin besar pada pihak luar, sehingga tidak disukai oleh investor dan dapat menyebabkan penurunan EPS.

Berdasarkan hasil pengolahan seperti yang terdapat pada tabel 4 diperoleh

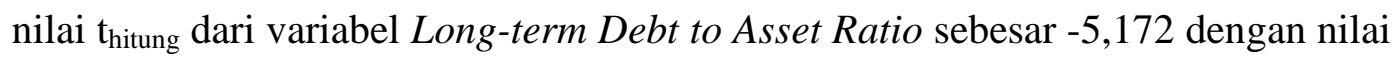
probability mendekati nol. Karena nilai absolut $t_{\text {hitung }}(5,172)$ lebih besar dari $t_{\text {tabel }}$ $(2,00)$, maka dengan tingkat kekeliruan 5\% diputuskan untuk mnolak Ho atau menerima Ha. Hal ini sejalan dengan Harahap (2012) yang menyatakan bahwa Long-term Debt to Asset Ratio memiliki pengaruh negative signifikan terhadap earning Per Share (EPS). Dengan demikian dapat disimpulkan bahwa Long-term 
Debt to Asset Ratio memiliki pengaruh terhadap Earning Per Share (EPS) namun berlawanan arah. Hasil pengujian empiris membuktikan bahwa semakin tinggi Long-term Debt to Asset Ratio cenderung akan menurunkan Earning Per Share pada perusahaan yang tergabung dalam Jakarta Islamic Index, karena perusahaan dinilai tidak mampu mengatasi kesulitan keuangan dengan meminjam hutang jangka panjang dalam jumlah yang besar.

\section{Uji F}

Tabel 5. ANOVA

\begin{tabular}{|c|c|c|c|c|c|c|}
\hline Model & & $\begin{array}{l}\text { Sum of } \\
\text { Squares }\end{array}$ & $\mathrm{df}$ & Mean Square & $\mathrm{F}$ & Sig. \\
\hline \multirow{3}{*}{1} & Regression & 41,451 & 3 & 13,817 & 10,236 & $.000^{b}$ \\
\hline & Residual & 75,593 & 56 & 1,350 & & \\
\hline & Total & 117,044 & 59 & & & \\
\hline
\end{tabular}

a. Dependent Variable: Ln_EPS

b. Predictors: (Constant), LTDR, DER, DAR

Sumber : Data diolah peneliti, 2017

Berdasrkan hasil pengolahan yang disajikan pada tabel 5 dapat dilihat nilai $F_{\text {hitung }}$ sebesar 10,236 dengan nilai signifikansi mendekati nol. Kemudian nilai $\mathrm{F}_{\text {tabel }}$ pada tingkat kekeliruan 5\% $(\alpha=0,05)$ dan derajat bebas 3 dan 56 adalah sebesar 2,77. Karena $F_{\text {hitung }}(10,236)$ lebih besar dari $F_{\text {tabel }}(2,77)$, maka pada tingkat signifikansi 5\% diambil keputusan untuk menolak Ho dan menerima Ha. Dengan demikian bisa ditarik kesimpulan bahwa Debt to Asset Ratio, Debt to Equity Ratio dan Long-term Debt to Asset ratio secara simultan berpengaruh terhadap Earning Per Share pada perusahaan yang tergabung dalam Jakarta Islamic Index.

\section{Hasil Analisis Koefisien Determinasi $\left(\mathbf{R}^{2}\right)$}

Tabel 6. Koefisien Determinasi Model Summary

\begin{tabular}{lrrrrr}
\hline Model & $\mathrm{R}$ & R Square & Adjusted R Square & $\begin{array}{c}\text { Std. Error of the } \\
\text { Estimate }\end{array}$ & Durbin-Watson \\
\hline 1 &, $595^{\mathrm{a}}$ &, 354 &, 320 & 1,16184 & 2,353
\end{tabular}

a. Predictors: (Constant), LTDR, DER, DAR

b. Dependent Variable: Ln_EPS 
Pada tabel 6 di atas dapat dilihat koefisien determinasi (adjusted R Square) sebesar 0,320 menunjukkan bahwa 32,0\% perubahan Earning Per Share pada perusahaan yang tergabung dalam Jakarta Islamic bisa dijelaskan atau disebabkan oleh Debt to Asset Ratio, Debt to Equity Ratio, dan Long-term Debt to Asset Ratio. Dengan kata lain Debt to Asset Ratio, Debt to Equity Ratio, dan Long-term Debt to Asset Ratio secara simultan memberikan pengaruh sebesar 32,0\% terhadap Earning Per Share, sedangkan sisanya yaitu sebesar 68,0\% dipengaruhi oleh faktor-faktor lain diluar Debt to Asset Ratio, Debt to Equity Ratio, dan Longterm Debt to Asset Ratio.

\section{Model Persamaan Regresi}

Guna menguji pengaruh Debt to Asset Ratio $\left(\mathrm{X}_{1}\right)$, Debt to Equity Ratio $\left(\mathrm{X}_{2}\right)$ dan Long-term Debt to Asset Ratio $\left(\mathrm{X}_{3}\right)$ terhadap Earning Per Share (Y) digunakan analisis regresi linier berganda. Karena nilai Earning Per Share antar perusahaan sangat bervariasi, maka agar data Earning Per Share lebih homogen dilakukan logaritma natural. Berdasarkan hasil pengolahan data menggunakan software SPSS 20 for windows, diperoleh hasil regresi Debt to Asset Ratio, Debt to Equity Ratio, dan Long-term Debt to Asset Ratio terhadap Earning Per Share sebagai berikut.

Tabel 7. Hasil Analisis Regresi

\begin{tabular}{|c|c|c|c|c|c|c|}
\hline \multicolumn{7}{|c|}{ Coefficients $^{\mathrm{a}}$} \\
\hline \multirow{2}{*}{\multicolumn{2}{|c|}{ Model }} & \multicolumn{2}{|c|}{$\begin{array}{l}\text { Unstandardized } \\
\text { Coefficients }\end{array}$} & \multirow{2}{*}{$\begin{array}{c}\text { Standardized } \\
\text { Coefficients } \\
\text { Beta } \\
\end{array}$} & \multirow[t]{2}{*}{$\mathrm{t}$} & \multirow[t]{2}{*}{ Sig. } \\
\hline & & B & Std. Error & & & \\
\hline \multirow{4}{*}{1} & (Constant) & 5,424 &, 568 & & 9,545 &, 000 \\
\hline & DAR &, 060 & ,035 &, 780 & 1,728 & ,090 \\
\hline & DER &,- 012 & ,009 &,- 551 & $-1,334$ & ,188 \\
\hline & LTDR &,- 079 & 015 &,- 756 & $-5,172$ &, 000 \\
\hline
\end{tabular}

Sumber : Data diolah peneliti, 2017

Melalui nilai unstandardized coefficients yang terdapat pada tabel 7 dapat dibentuk persamaan regresi Debt to Asset Ratio, Debt to Equity Ratio, dan Longterm Debt to Asset Ratio terhadap Earning Per Share sebagai berikut.

$$
\mathrm{Y}=\mathbf{5 , 4 2 4}+\mathbf{0 , 0 6 0} \mathrm{X}_{1}-\mathbf{0 , 0 1 2} \mathrm{X}_{2}-\mathbf{0 , 0 7 9} \mathrm{X}_{3}
$$


Dari persamaan tersebut dapat dilihat bahwa koefisien regresi variable Debt to Asset Ratio sebesar 0,060 bertanda positif yang berarti setiap Debt to Asset Ratio sebesar 1\% maka Earning Per Share akan meningkat sebesar Rp 0,060. Kemudian koefisien regresi variable Debt to Equity Ratio sebesar 0,012 bertanda negatif yang berarti kenaikan Debt to Equity Ratio sebesar 1\% maka Earning Per Share akan turun sebesar Rp 0,012. Koefisien regresi variabel Longterm Debt to Asset Ratio sebesar 0,079 bertanda negatif yang berarti setiap kenaikan Long-term Debt to Asset Ratio sebesar 1\% maka Earning Per Share akan menurun sebesar Rp 0,079. Konstanta sebesar 5,424 menunjukkan nilai ratarata Earning Per Share perusahaan yang tergabung pada Jakarta Islamic Index pada saat DAR, DER dan LDAR bernilai 0 .

\section{SIMPULAN DAN SARAN}

\section{Kesimpulan}

1) Debt to Asset Ratio memiliki koefisien bertanda positif, namun dari hasil pengujian Debt to Asset Ratio tidak berpengaruh terhadap Earning Per Share Jakarta Islamic Index (JII) periode 2011-2016.

2) Debt to Equity Ratio memiliki koefisien bertanda negatif, akan tetapi dari hasil pengujian Debt to Equity Ratio tidak berpengaruh terhadap Earning Per Share Jakarta Islamic Index periode 2011-2016.

3) Long-term debt to Asset Ratio berpengaruh negatif terhadap Earning Per Share Jakarta Islamic Index periode 2011-2016. Semakin tinggi Long-term Debt to Asset Ratio cenderung akan menurunkan Earning Per Share pada perusahaan yang tergabung dalam Jakarta Islamic Index.

4) Debt to Asset Ratio, Debt to Equity Ratio dan Long-term Debt to Asset Ratio secara simultan berpengaruh terhadap Earning Per Share pada perusahaan yang tergabung dalam Jakarta Islamic Index. Secara simultan Debt to Asset Ratio, Debt to Equity Ratio dan Long-term Debt to Asset Ratio memberikan pengaruh sebesar 32,0\% terhadap Earning Per Share.

\section{Saran}

1) Bagi perusahaan 
Perusahaan sebaiknya memperhatikan komposisi struktur modal khusunya proporsi antara hutang jangka panjang dengan total asset. Hutang yang tidak terlalu besar akan membuat perusahaan menghadapi risiko yang tidak besar pula, sehingga akan menarik investor untuk berinvestasi dengan tidak meminta pengembalian dalam jumlah yang besar agar dapat meningkatkan nilai Earning Per Share.

2) Bagi investor

Sebaiknya para investor mempertimbangkan komposisi struktur modal yang seimbang dalam melakukan penilaian investasi. Struktur modal dengan hutang yang besar akan berisiko bagi investor tersebut. Investor sudah semestinya berhati-hati dalam mengambil keputusan agar mendapatkan pilihan yang tepat untuk menanamkan modalnya.

\section{DAFTAR PUSTAKA}

Brigham, Eugene F, dan Houston, Joel F. (2011). Dasar-dasar Manajemen Keuangan Terjemahan. Edisi 10. Jakarta: Salemba Empat.

Fina Karmila. (2016). Pengaruh Financial Leverage terhadap Earning Per Share pada Perusahaan Telekomunikasi di BEI Periode 2009-2014. Ejournal Administrasi Bisnis, Volume 4, Nomor 2, 2016: 521-534.

http://ejournal.adbisnis.fisip-unmul.ac.id/site/wpcontent/uploads/2016/06/JURNALpdf\%20(06-21-16-03-09-48).pdf

Gitman, Lawrence J, and Zutter, Chad J. (2012). Principles of Management Finance. $13^{\text {th }}$ Edition. Edinburgh: Pearson.

Gitman, Lawrence J. (2012). Principles of Managerial Finance. Global Edition. Pearson Education Limited.

Hanafi, Mamduh M. (2014). Manajemen Keuangan. Edisi 1. Yogyakarta: BPFEYogyakarta.

Harahap, Baleo Martua. (2012). Pengaruh Perubahan Financial Leverage Terhadap Tingkat Earning Per Share Pada Perusahaan Perkebunan dan Pertambangan yang Terdaftar di Bursa Efek Indonesia.

http://repository.usu.ac.id/bitstream/handle/123456789/58329/Cover.pdf?sequenc e=7\&isAllowed $=\mathrm{y}$ 
Harahap, Sofyan Syafri. (2013). Analisis Kritis Atas Laporan Keuangan. Edisi 1. Jakarta: PT. Raja Grafindo Persada.

Hery. (2016). Analisis Laporan Keuangan. Jakarta: Grasindo.

Horen, James C. Van dan Jonh M. Wachowicz, Jr. (2012). Prinsip-prinsip Manajemen Keuangan. Edisi 13. Jakarta: Salemba Empat.

Kasmir. (2014). Analisis Laporan Keuangan. Jakarta: Raja Grafindo Persada.

Mohamad, Yulinda and Se, Hais dama and Se, Idham Masri Ishak. (2015). Pengaruh Debt Ratio (DR) dan Debt to Equity Ratio (DER) terhadap Earning Per Share (EPS) Pada Perusahaan Sektor Farmasi di Bursa Efek Indonesia periode 2013-2014.

Sjahrial, Dermawan dan Djahotman Purba. (2013). Analisis Laporan Keuangan. Jakarta: Mitra Wacana Media.

Sjahrial, Dermawan. (2014). Manajemen Keuangan Lanjutan. Edisi Revisi. Jakarta: Mitra Wacana Media.

Sugiyono, (2013). Metode Penelitian Manajemen. Bandung: Alfabeta.

Sutrisno, (2012). Manajemen Keuangan Teori, Konsep, dan Aplikasi. Edisi Kedelapan. Yogyakarta: Ekonisia.

Internet:

http://www.idx.co.id

https://www.sahamok.com

http://www.bareksa.com/id/text/2015/12/18/chart-of-the-day-5-tahun-terakhirkinerja-

kumpulan-saham-syariah-dibawah-ihsg/12224/news 